\title{
Augmenting Public Health Surveillance with Big Data: Measurement Framework and Selected Applications
}

\author{
Dominic Vincent Ligot, CirroLytix Research Services \\ (email: dominic.ligot@cirrolytix.com)
}

\begin{abstract}
This paper examines opportunities for big data in augmenting public health surveillance. We describe the use of social listening, remote sensing and mobility indices in supplementing surveillance data. We discuss the time varying reproductive number as an alternative to the basic reproductive number for monitoring an ongoing pandemic, present the INFORM risk management model for integrating insights, and discuss modalities for decision support systems. Selected examples of big data surveillance applications are presented along with considerations for further work.
\end{abstract}

Keywords: surveillance, public health, SIR, remote sensing, social listening, big data, crowdtangle, facebook, twitter, google search trends, mobility, reproductive number

\section{Introduction}

COVID-19 accelerated the shift of the global economy towards online and e-ecommerce (UNCTAD, 2021) (De, Pandey, \& Pal, 2020). Despite the increased trend towards digitalization and continued advances in machine learning and artificial intelligence, prospects for big data in public health remain in a generally nascent state globally due to concerns related to data sharing, innovation incentives, data privacy, and skills shortage (Buckee, 2020). Despite this, opportunities for the application of big data continue to emerge (Bansal, Chowell, Simonsen, Vespignani, \& Viboud, 2016) and it is against this backdrop that we present some recent work and learnings in the field.

Section 2 will review the standard practices in public health data gathering and discuss common challenges that beset public health surveillance. We dive into big data in Section 3, discussing the potential for social listening, remote sensing, and mobility indices to complement and enhance public health data gathering. Section 4 presents key elements in building a big data measurement framework. In Section 5, we present selected examples of big data brought to bear on surveillance. Section 6 summarizes our discussion and presents considerations for further work.

\section{Data gathering in public health}

Data collection methods in public health include rapid assessment, surveys, and surveillance. Rapid assessments involve qualitative and quantitative data collection, often though convenience samples at a single point in time. Surveys are focused on quantitative data collection, usually on a statistical sample of a population of interest at a single point in time. Calculating prevalence and incidence rates for surveys are easier than rapid assessments since sampling provides both numerator and denominator while rapid assessments collect numerators only. Surveillance also collects quantitative 
data like surveys but focuses on obtaining data on every case of illness. Unlike rapid assessments and surveys, surveillance collects longitudinal data for trend analysis, but similar to rapid assessments surveillance obtains numerators only, denominators are obtained from a separate source to calculate prevalence and incidence rates (Woodruff, Bornemisza, Checchi, \& Sondorp, Comparison with other data collection methods, 2009).

Surveillance is targeted at diseases with substantial morbidity and rapidly developing outbreaks such as COVID-19. Health surveillance modalities include passive, active, and sentinel surveillance. Passive surveillance is reactive involving minimal data, obtaining information from all health care workers but without any stimulus. In passive surveillance, if no data is reported, authorities assume zero cases unlike in active surveillance which involves complete case counts, including reports of zero cases. Active surveillance involves proactive efforts to seek out cases of specific diseases through health care providers, schools, and labs rather than reactively waiting for case reports. Active surveillance can involve incentives and feedback to health care workers to report cases as well as proactive feedback and monitoring, requiring substantially more time and resources, especially during the early stages of an epidemic outbreak. Sentinel surveillance selects a sample of health care workers to gather information from, with greater attention than what would be involved in active surveillance. Data gathered under sentinel surveillance is detailed data on cases of illness with health care workers proactively agreeing to participate with incentives for participation (Woodruff, Bornemisza, Checchi, \& Sondorp, Types of surveillance, 2009). Passive, active, and sentinel surveillance involve diagnostic data with confirmed cases, while syndromic surveillance collects data on symptoms through automated data feeds in real time or close to real time, providing a leading indicator or early warning of an outbreak (Stone \& Horney, 2018).

\section{Challenges in public health surveillance}

As data gathering methods are focused on positive case counts, calculating prevalence is a common challenge in public health surveillance due to the lack of an available denominator. Detection is centered on health care provider locations, which excludes cases that never sought proper treatment. Despite incentives, reporting is solely dependent on the initiative and capacity of health care workers to provide information, which may be outside their job descriptions. The result is a highly biased and often incomplete account of a disease spread until well into outbreak when more attention is put on surveillance (Woodruff, Bornemisza, Checchi, \& Sondorp, Incomplete reporting, 2009). Surveillance systems are primarily manual in nature and involve a lot of time and effort to gather and disseminate. Granularity of the reporting tends to aggregate at regional or national level, which challenges public health response at the local level (Bansal, Chowell, Simonsen, Vespignani, \& Viboud, 2016).

\section{Big Data}

The challenges of standard public health surveillance presents the opportunity for big data, which until now remains non-traditional in a public health setting. A clear potential for big data enabled surveillance includes real-time tracking of population behavior and environmental factors that affect the spread of epidemics (Buckee, 2020). The three "V"s of volume (physical size, e.g. terabytes), velocity (frequency of update, e.g. real-time), and variety (multiple forms, e.g. structured, semistructured, unstructured) are often used to describe big data (Bansal, Chowell, Simonsen, Vespignani, \& Viboud, 2016).

Although widespread adoption is still nascent, big data has been used in a public health context. Electronic data streams from medical encounter data, to participatory syndromic data, to non-health digital data have been in use in public health response (Bansal, Chowell, Simonsen, Vespignani, \& 
Viboud, 2016). Data from mobile phones, remote sensing, and social media have also been considered for use in outbreak monitoring and modeling (Buckee, 2020).

In this section we will share uses of social listening, remote sensing, and mobility indices in augmenting surveillance systems.

\section{Social Listening}

Social listening refers to online data from social network media platforms such as Facebook and Twitter (Hussain, et al., 2020) as well as search trends from Google (Davidson, Haim, \& Radin , 2015). Time-series data from online platforms can be extracted for analysis against public health surveillance data.

Extracted using their native application programming interfaces (API) or third party services such as Crowdtangle (CrowdTangle Team, 2021) (Hussain, et al., 2020), data from Facebook and Twitter are rich sources of text and semantic data. When subjected to topic modeling and sentiment analysis, social media posts can provide statistical information on prevailing public discourse (Hamzah, Lau, Nazri, \& Ligot, 2020), speed of dissemination, and related communication networks (Ligot D. , Tayco, Toledo, Nazareno, \& Brennan-Rieder, 2021).
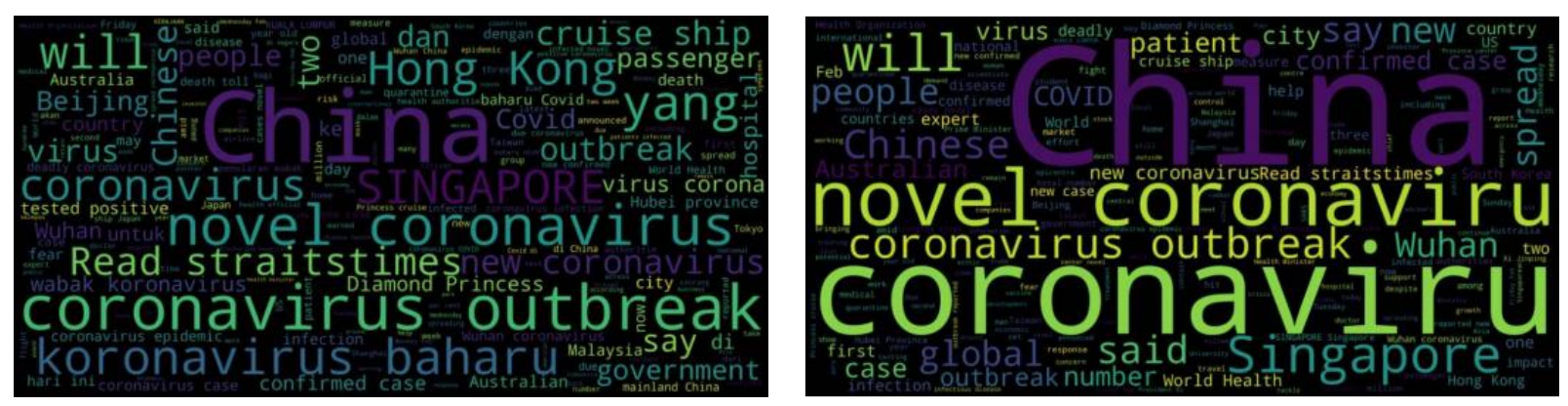

Figure 1: Word Clouds from COVID-19 Twitter Posts ${ }^{1}$

Google Search Trends is an openly extractable statistic of topic interest and relevance culled from search frequency on the Google Search Engine. As a measure of topic interest, search trends for diseases and related terms (e.g. medicine, symptoms, locations) can be correlated with case incidence growth rates and epidemiological indicators to contextualize an outbreak or serve as early warning or confirmatory indicators. Search trends have been used to nowcast the spread of outbreaks such as influenza (Davidson, Haim, \& Radin , 2015) and dengue (Yang, et al., 2017).

${ }^{1}$ (Hamzah, Lau, Nazri, \& Ligot, 2020) 


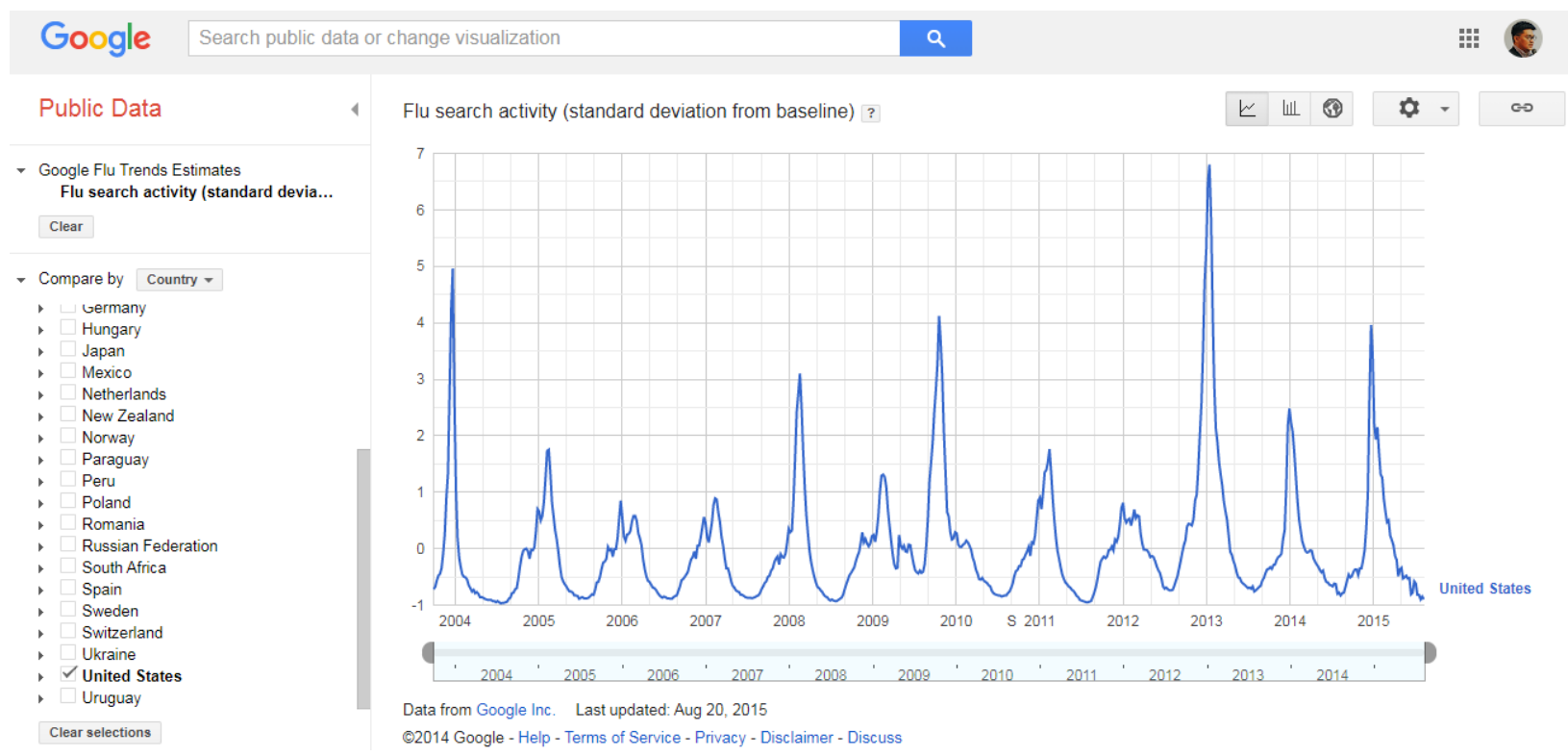

Figure 2: Google Flu Trends ${ }^{2}$

\section{Remote Sensing}

Remote sensing refers to data from Earth observing satellites, which provide indications of ground conditions and environmental factors that can contextualize health and outbreaks (Jovanovic, 1987). Remote sensing measures electromagnetic energy from the surface to observe and measure ground conditions (NASA, What is Remote Sensing?, 2021). Passive sensing measures natural energy or radiation such as from the Sun reflected by the Earth's surface while active sensing projects energy to illuminate objects and measures the reflection or backscattering (NASA, Remote Sensors, 2021).

Categories of remote sensing indicators include ground moisture, vegetation, air quality, temperature, and climate hazards such as flooding (NASA, Worldview, 2021). The advent of webbased tools such as Google Earth Engine (Google, Google Earth Engine, 2021) and ESA's Sentinel HUB (Sinergise, 2021) allow the easier extraction of time-series data for a particular area of interest, which can integrate into a surveillance framework. Web-based protocols such as WMS (Web Map Service) allow remote sensing indicators to be overlaid on maps for geospatial and topographical analysis (Cechini, 2021).

2 (Google, Google Flu Trends, 2015) 


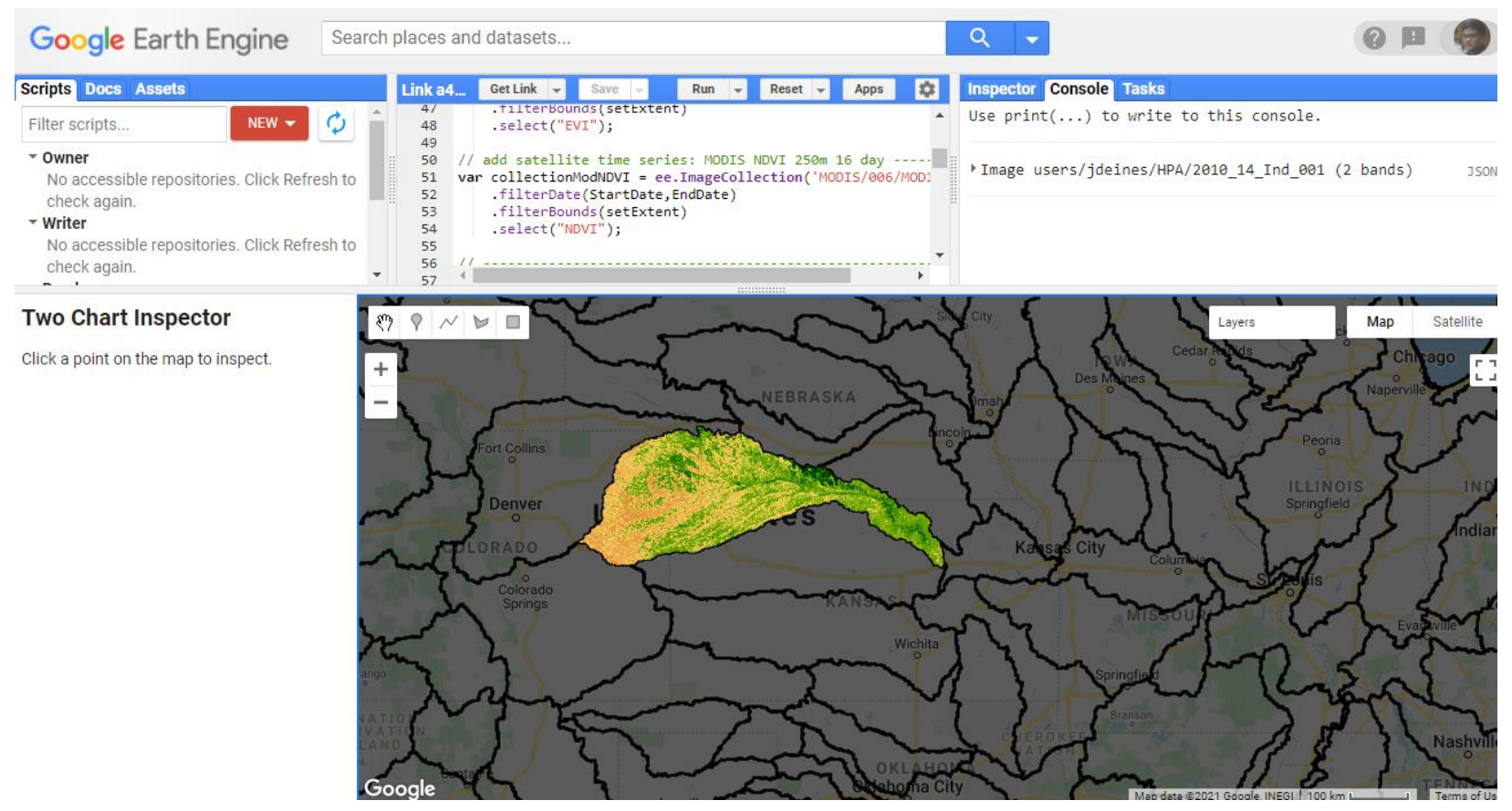

Figure 3: Google Earth Engine Interface 3

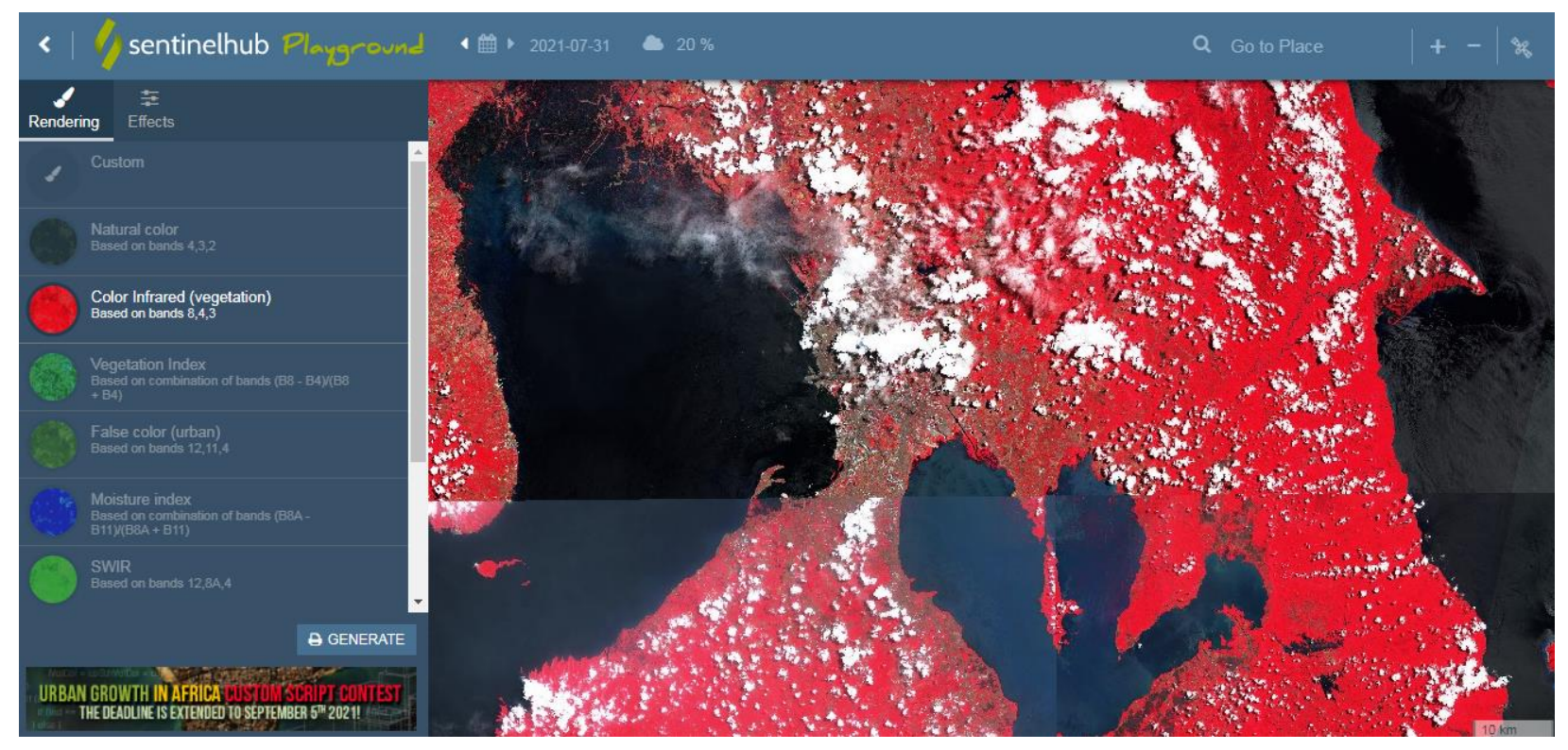

Figure 4: Sentinel Hub Playground Interface 4

3 (Google, Google Earth Engine, 2021)

4 (Sinergise, 2021) 


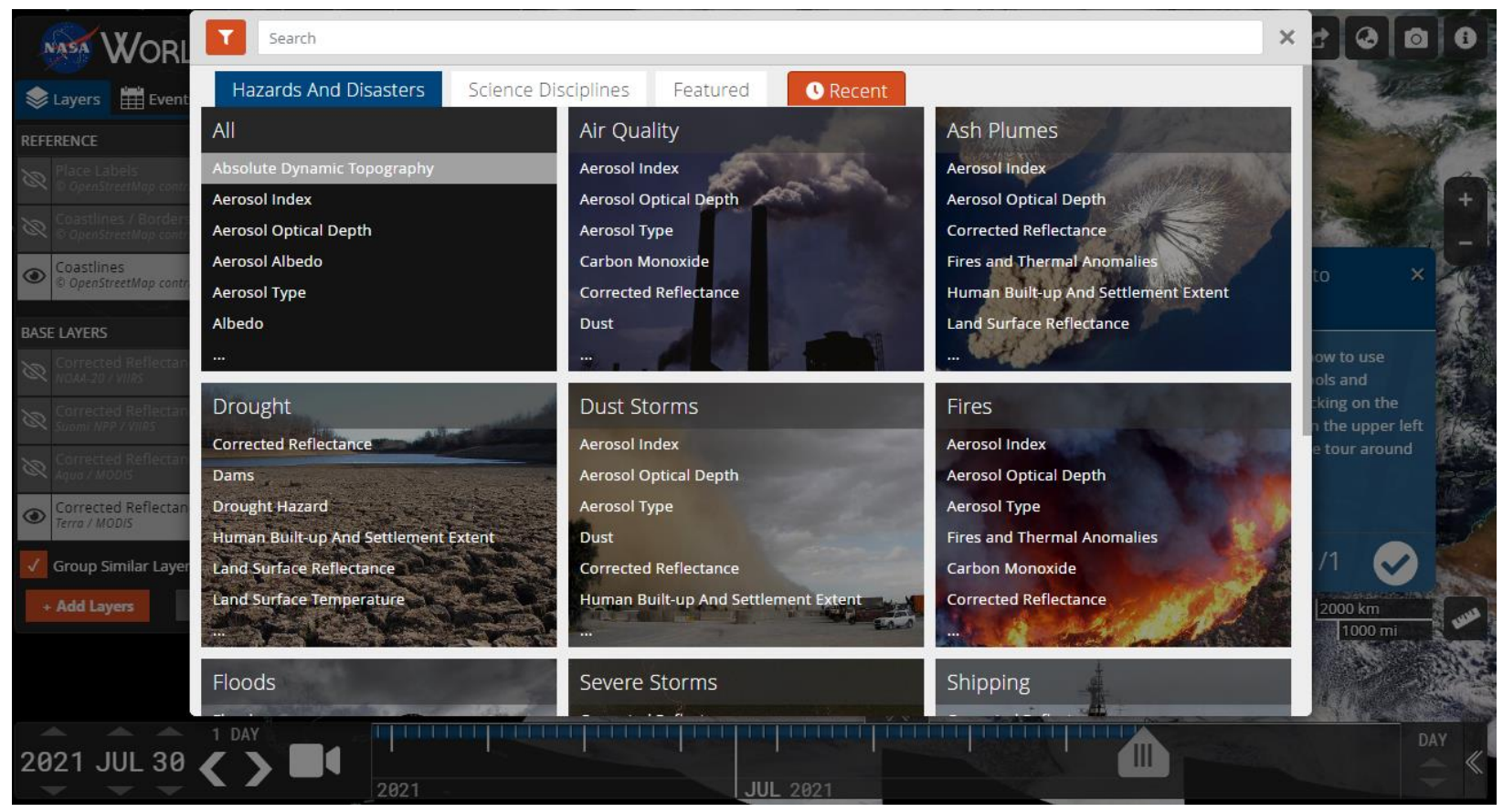

Figure 5: NASA Worldview5

\section{Mobility}

Since the COVID-19 pandemic forced countries into imposed lockdowns, tech companies such as Apple, Google, and Facebook have begun publishing data on public mobility. Apple and Google report movement detected from mobile phones, Apple aggregates this by user activity such as Walking, Driving, or in Transit (Apple, 2020-2021) while Google aggregates by inferred location such as Residential, Retail, Grocery, Parks, Workplaces, and Transit (Google, COVID-19 Community Mobility Reports, 2020-2021). Facebook reports movement inferred from users moving into and out of locational polygons and proportion of users staying put within a single location (Facebook, 20202021).

Time series of mobility indices correlated with the incidence or growth rates of an outbreak, can measure of the effectiveness of or compliance to lockdown measures imposed in a location (Barrameda, Zapata, Tan, \& Castelo, 2020).

5 (NASA, Worldview, 2021) 


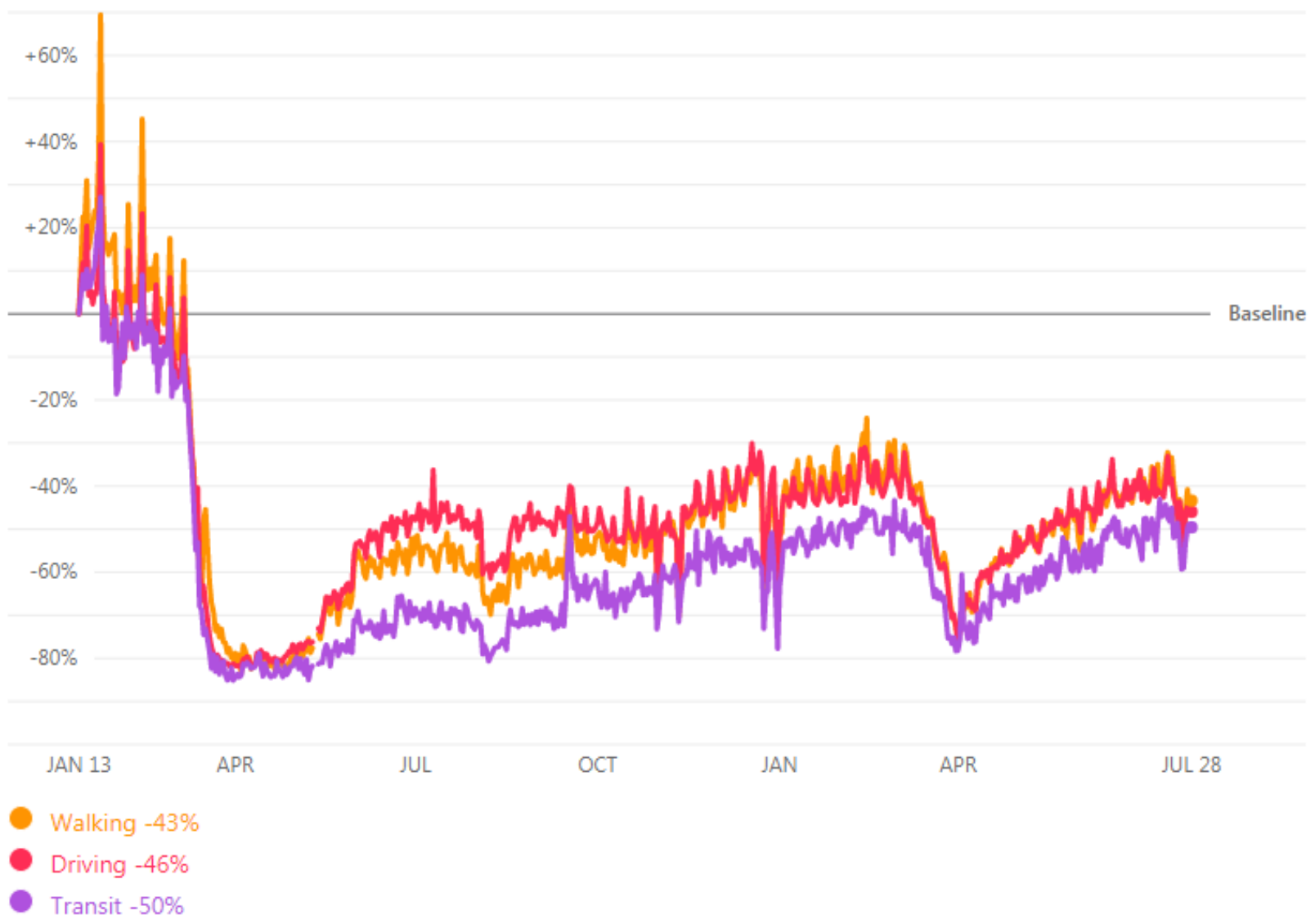

Figure 6: Apple Mobility Trends Report ${ }^{6}$

\section{Big Data Measurement Framework}

In this section we discuss some key elements for a big data measurement framework, first illustrating Time Varying $\mathrm{R}$ as an example of an ideal performance indicator, then we discuss the INFORM risk management model as a framework for integrating other information to contextualize surveillance data, and we will discuss modalities for using data to power decision support systems.

\section{Pandemic Performance Indicator: Time Varying R}

To illustrate a common challenge in epidemic measurement, let us consider compartmental models, which are part of the standard epidemiology toolkit. These models divide the population in to compartments, and the transition or flow between compartments used as indicators to gauge the epidemic spread. The simplest form of epidemic compartmental model is the SIR (Susceptible, Infectious, and Recovered) framework. In SIR, $\beta$ is the transition rate of individuals from the Susceptible to Infectious population, while $\gamma$ is the recovery rate which measures the transition of individuals from Infectious to Recovered (van den Driessche, 2017).

6 (Apple, 2020-2021) 
The reproductive number $(\mathrm{R})$ is a measure of the transmissibility or contagiousness of an infectious disease, on average how many people will contract the disease from a single infectious person. An $\mathrm{R}$ above 1 indicates a spreading epidemic, while below 1 indicates an declining one. Using transition rates between compartments, a basic reproductive number $\left(R_{0}\right)$ can be calculated which serves as a measure of the transmissibility of a disease (Keeling \& Rohani, 2008).

$$
\begin{aligned}
& \text { Equation 1: Basic Reproductive Number }\left(R_{0}\right)^{7} \\
& \qquad R_{0}=\frac{\beta}{\gamma}
\end{aligned}
$$

The following table illustrates the basic reproductive numbers of some infectious diseases (van den Driessche, 2017) including COVID-19 for comparison (Hilton \& Keeling, 2020).

Table 1: Selected $R_{0}$ numbers

\begin{tabular}{ll} 
Disease (Location, Year) & \\
\hline Smallpox (India, 1968-73) & $R_{0}$ \\
Poliomyelitis (Europe, 1955-60) & 4.5 \\
Measles (Ghana, 1960-68) & 6 \\
SARS (2002-03) & 14.5 \\
Spanish Influenza (Geneva, 1918) & 3.5 \\
H2N2 influenza (US, 1957) & $1.5-3.8$ \\
H1N1 influenza (South Africa, 2009) & 1.68 \\
Ebola (Guinea, 2014) & 1.33 \\
Zika (South America, 2015) & 1.51 \\
COVID-19 (2020- $)^{9}$ & 2.06 \\
\hline
\end{tabular}

While mathematically efficient, compartmental models suffer from the denominator problem of public health surveillance. The susceptible population for a given disease is hard to establish especially at the early stages of an outbreak. Establishing the actual population "at-risk" can only be approximated even with active surveillance and considering the entire population of a given location would dramatically understate the $R_{0}$ (Cori, Ferguson, Fraser, \& Cauchemez, 2013). Models such as the SIR without adjustment also naively assume that the population is "well-mixed" (Cooper, Mondal, \& Antonopoulos, 2020).

In practice, the frequency and freshness of the case reporting within the compartments are often not in-sync. Recovered cases are reported with considerable delay while confirmed infections are reported more earnestly via active surveillance. This natural mis-timing of reporting skews transition rates and the resulting $R_{0}$ for monitoring.

As an alternative, during an ongoing outbreak, a time-varying reproductive number $\left(R_{t}\right)$ has been used as a more manageable indicator of transmissibility (Cori, Ferguson, Fraser, \& Cauchemez, 2013). $R_{t}$ requires confirmed case incidence counts from active surveillance, and calculated as the ratio of new infections $E\left[I_{t}\right]$ to the sum of past infection incidence weighted by an infectivity function $\sum_{s=1}^{t} I_{t-s} w_{s}$. This enables a quicker generation of a rolling performance metric to measure the strength of an ongoing epidemic against which to gauge public health interventions.

7 (Keeling \& Rohani, 2008)

8 (van den Driessche, 2017), except COVID

9 (Hilton \& Keeling, 2020) 
Equation 2: Time varying reproductive number $\left(R_{t}\right)^{10}$

$$
R_{t}=\frac{E\left[I_{t}\right]}{\sum_{s=1}^{t} I_{t-s} w_{s}}
$$

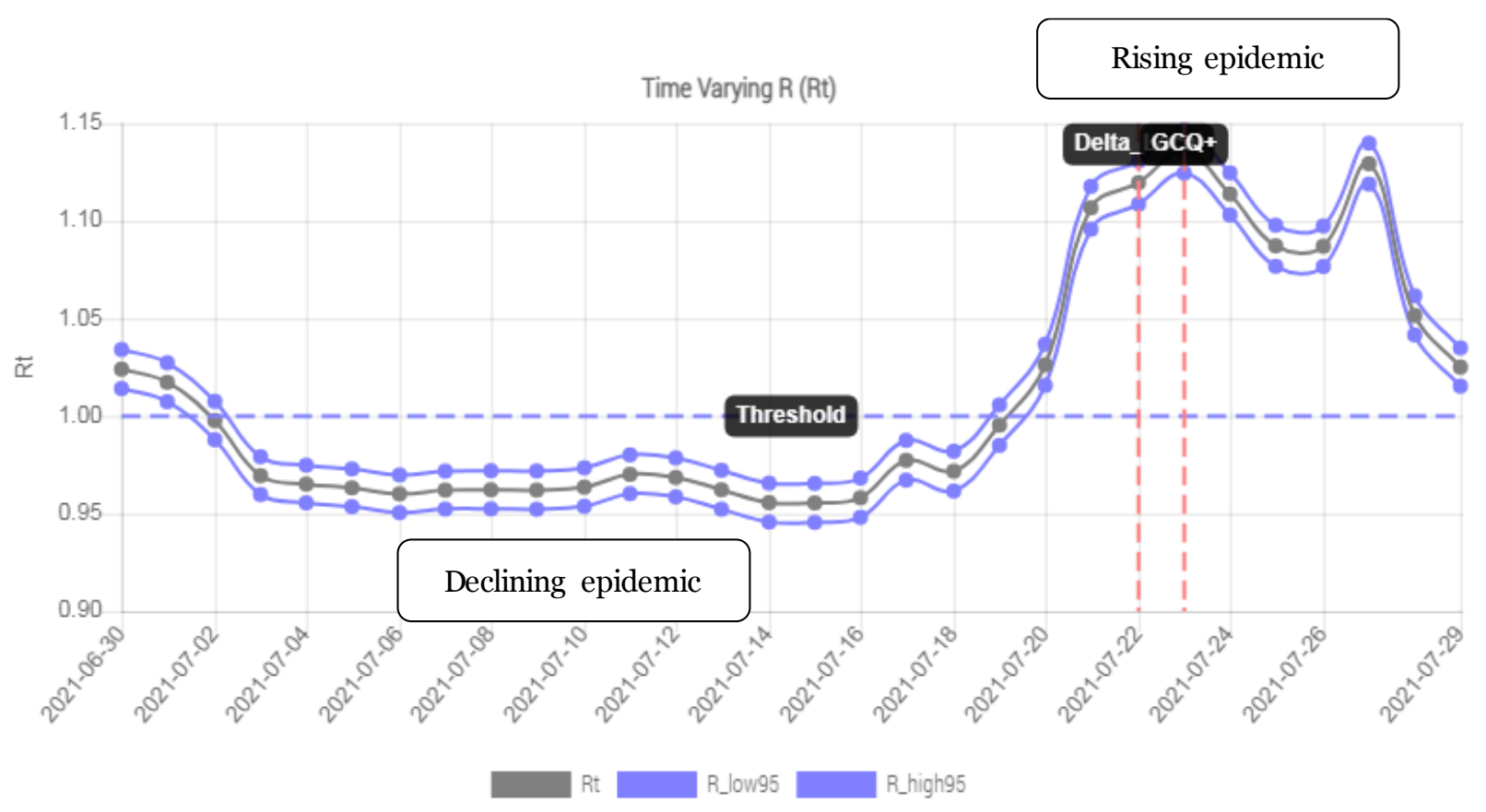

Figure 7: Time Varying $R\left(R_{t}\right)$ Trend $^{11}$

\section{Risk Management}

Risk management provides a conceptual framework for integrating a wide variety of information with surveillance data. An example is INFORM, developed by the EU JRC, which framework that looks at risk from three dimensions: hazards and exposures, vulnerability, and lack of coping capacity (Marin-Ferrer, Vernaccini, \& Poljansek, 2017). More recently, JRC has also developed frameworks specifically addressing epidemic risk (Doherty, Marin-Ferrer, \& Vernaccini, 2018) and COVID (Poljansek, Vernaccini, \& Marin-Ferrer, 2020).

Big data from social listening, remote sensing, and mobility combined with surveillance data and national statistical databases can populate the dimensions of risk within INFORM. A combined multi-dimensional dataset not only provides context for the development of an ongoing epidemic but can also guide public health response and policy.

10 (Cori, Ferguson, Fraser, \& Cauchemez, 2013)

${ }^{11}$ (Cayton, et al., 2020-2021) 


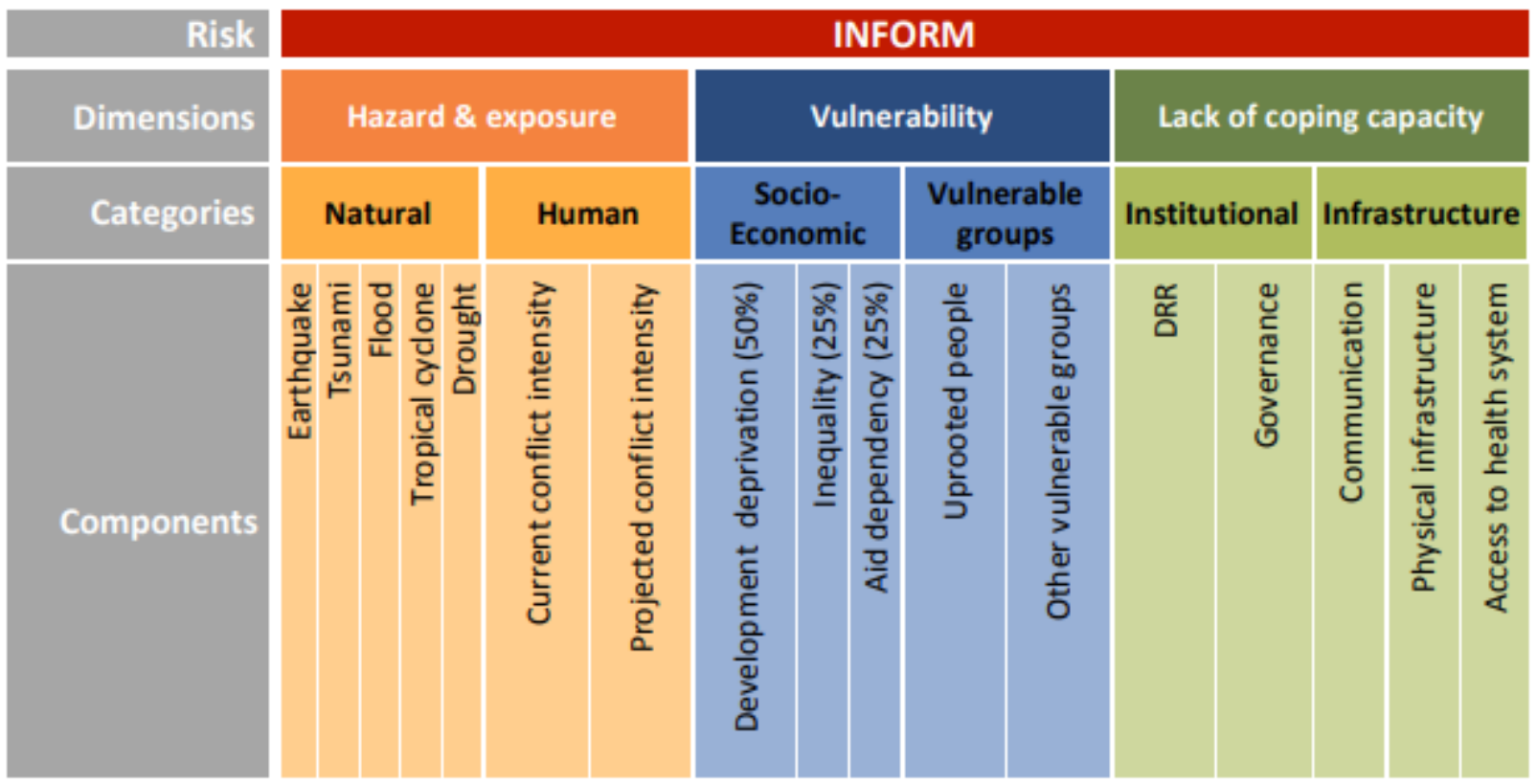

Figure 8: INFORM Risk Framework ${ }^{12}$

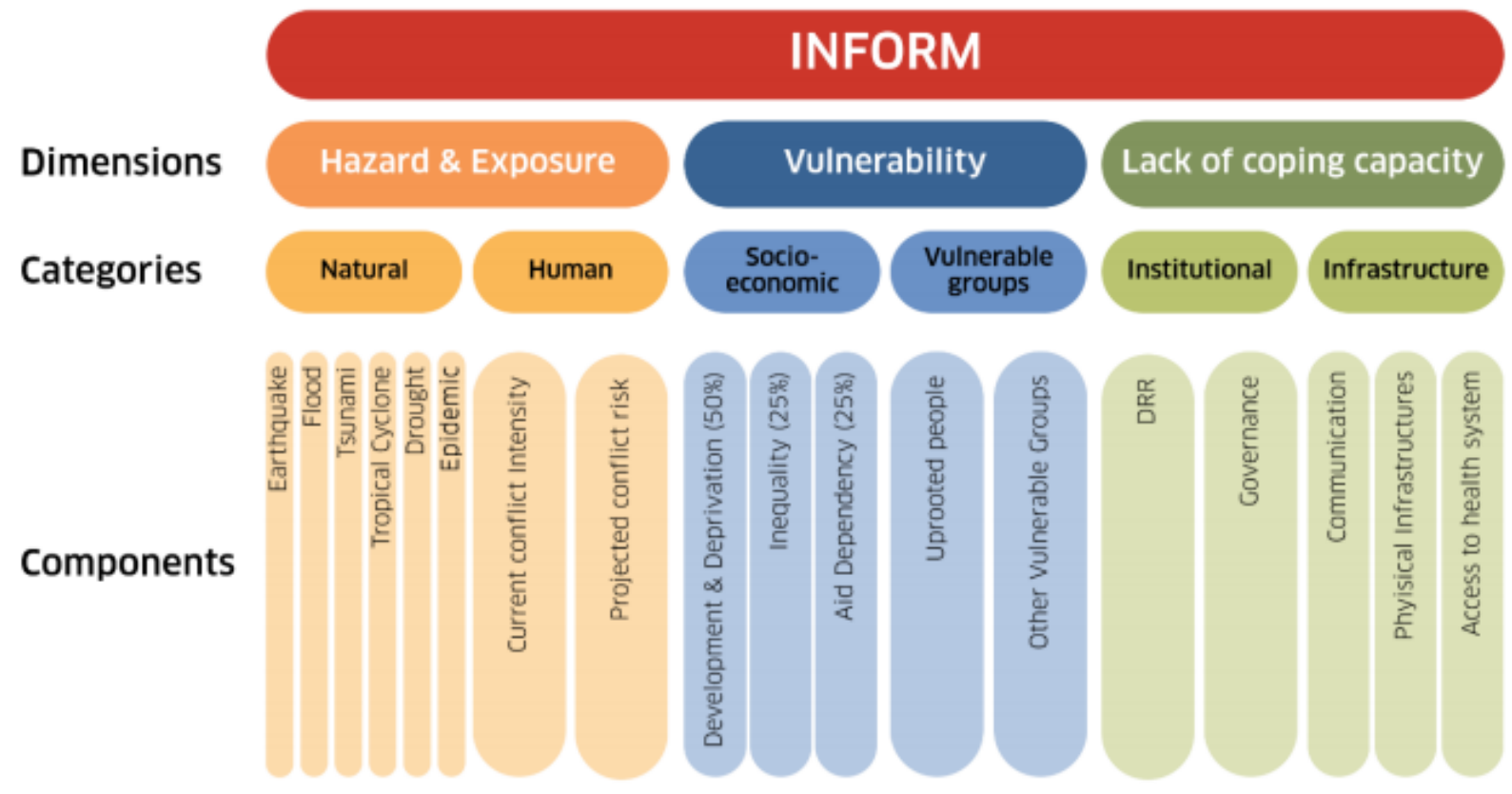

Figure 9: INFORM Epidemic Risk Framework ${ }^{13}$

\section{Decision Support Systems}

With epidemiological indicators such as $R_{t}$ contextualized by big data through a risk management framework, we now have the foundation for building decision support systems. These systems can be

12 (Marin-Ferrer, Vernaccini, \& Poljansek, 2017)

13 (Doherty, Marin-Ferrer, \& Vernaccini, 2018) 
knowledge- or expert-based but augmented by data and computational processing and automation (Hopgood, 2000).

Even using the same underlying datasets, decisions systems can vary in scope. While standard public health surveillance focuses on the trend of an outbreak, big data and risk management powered systems can assume several modalities summarized below. Modalities are not mutually exclusive, and decision support can combine approaches in the context of health surveillance.

Table 2: Decision support modalities

\begin{tabular}{lll}
\multicolumn{1}{c|}{ Decision Support } & \multicolumn{1}{c}{ Analytical Approach } & \multicolumn{1}{c}{ Big Data Use-cases } \\
\hline Diagnostic & $\begin{array}{l}\text { Determine the nature of a hazard based on a set of } \\
\text { facilitating and mitigating factors, involving root- } \\
\text { cause and multivariate analysis. }\end{array}$ & $\begin{array}{l}\text { Determinants or root causes from } \\
\text { social media or mobility, or } \\
\text { environmental factors from remote } \\
\text { sensing. }\end{array}$ \\
Design & $\begin{array}{l}\text { Prioritize tasks through ranking, scoring, and } \\
\text { trade-off optimization. }\end{array}$ & $\begin{array}{l}\text { Rank locations based on social media } \\
\text { sentiment, population movement, or } \\
\text { environmental risk factors. }\end{array}$ \\
Planning & $\begin{array}{l}\text { Forecasting, trend analysis, simulations, and } \\
\text { scenario generation to optimize future } \\
\text { interventions. }\end{array}$ & $\begin{array}{l}\text { Project trend of ongoing epidemic } \\
\text { driven by social media engagement, } \\
\text { google search trends, or trends in } \\
\text { environmental factors such as } \\
\text { pollution. }\end{array}$ \\
& $\begin{array}{l}\text { Trend direction, threshold management, anomaly } \\
\text { direction. }\end{array}$ & $\begin{array}{l}\text { Monitor epidemic alerts based on } \\
\text { online sentiment, changes in climate } \\
\text { or mobility thresholds. }\end{array}$ \\
Control & &
\end{tabular}

\section{Selected Applications}

In this section, we present some recent work in deploying big data surveillance systems. Many of these applications were entries in data-driven competitions such as the NASA International Space Apps Challenge and EO Dashboard Hackathons, which encourage the use of remote sensing and non-traditional datasets in solving social and environmental challenges.

\section{$\mathrm{L} 4 \mathrm{H}$}

Launched in 2020 at the early stages of the COVID-19 pandemic in the Philippines, the $\mathrm{L} 4 \mathrm{H}$ dashboard features epidemiological indicators such as $R_{t}$ as well as the CO-INFORM risk framework adapted from the JRC model for COVID. The dashboard tracks the progress of the COVID epidemic in the Philippines daily, and helps prioritize high-risk areas for COVID. L4H is a collaboration between various Philippine academic institutions, the Philippine Society for Public Health Physicians (PSPHP), and CirroLytix (Cayton, et al., 2020-2021). 
Epidemic Indicators

Select KPI Date:

2021-07-29

Select Trend Chart:

Time Varying R (Rt)

Chart Time Period: Past 30 days

Time Varying R (Rt)

Related to the basic reproductive number (Ro), the effective reproductive number is the transmission rate of the virus at time ( $\mathrm{t}$ ). Threshold for Rt is 1.0, if for consecutive days $R t$ is below 1.0 it suggests that the community has started to effectively control the spread of the disease.
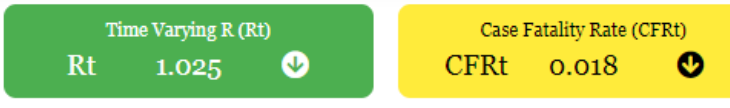

Crude Recovery Rate (CRRt)

CRRt $0.947 \quad$ ๖

$\left.\begin{array}{ccc}\text { \% Growth Cases } \\ 0.359\end{array}\right)$

$\begin{array}{ccc}\text { \% Growth Deaths } & \\ \% & 0.642 & \boldsymbol{P}\end{array}$

96 Growth Recoveries

$\% \quad 0.251$

○

Time Varying R (Rt)

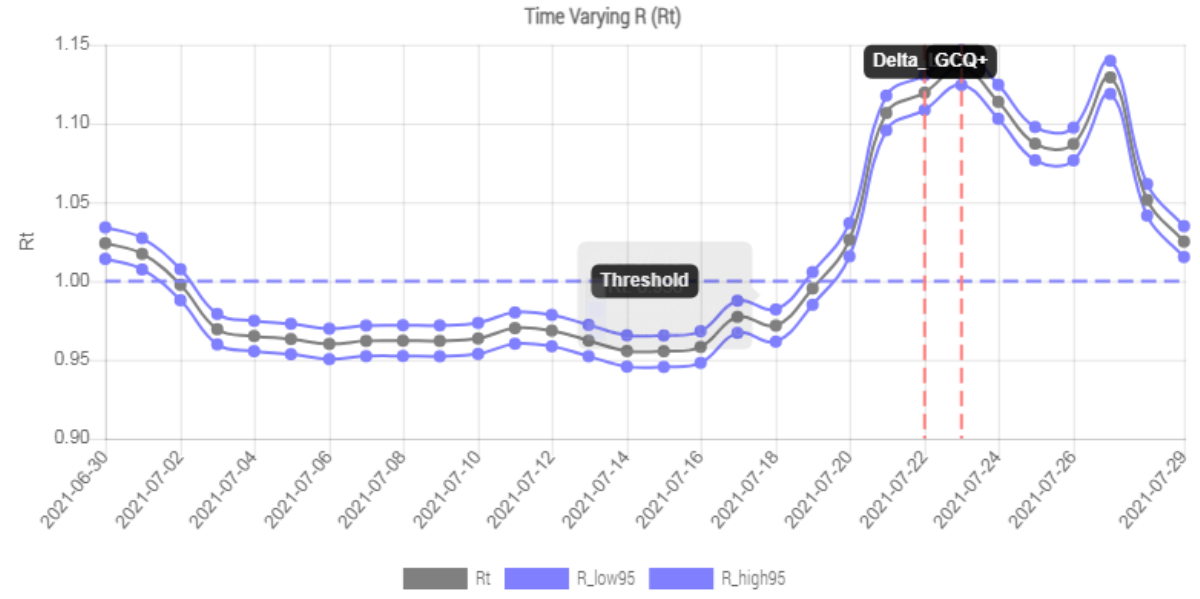

Figure 10: L4H Epidemic Indicator Dashboard

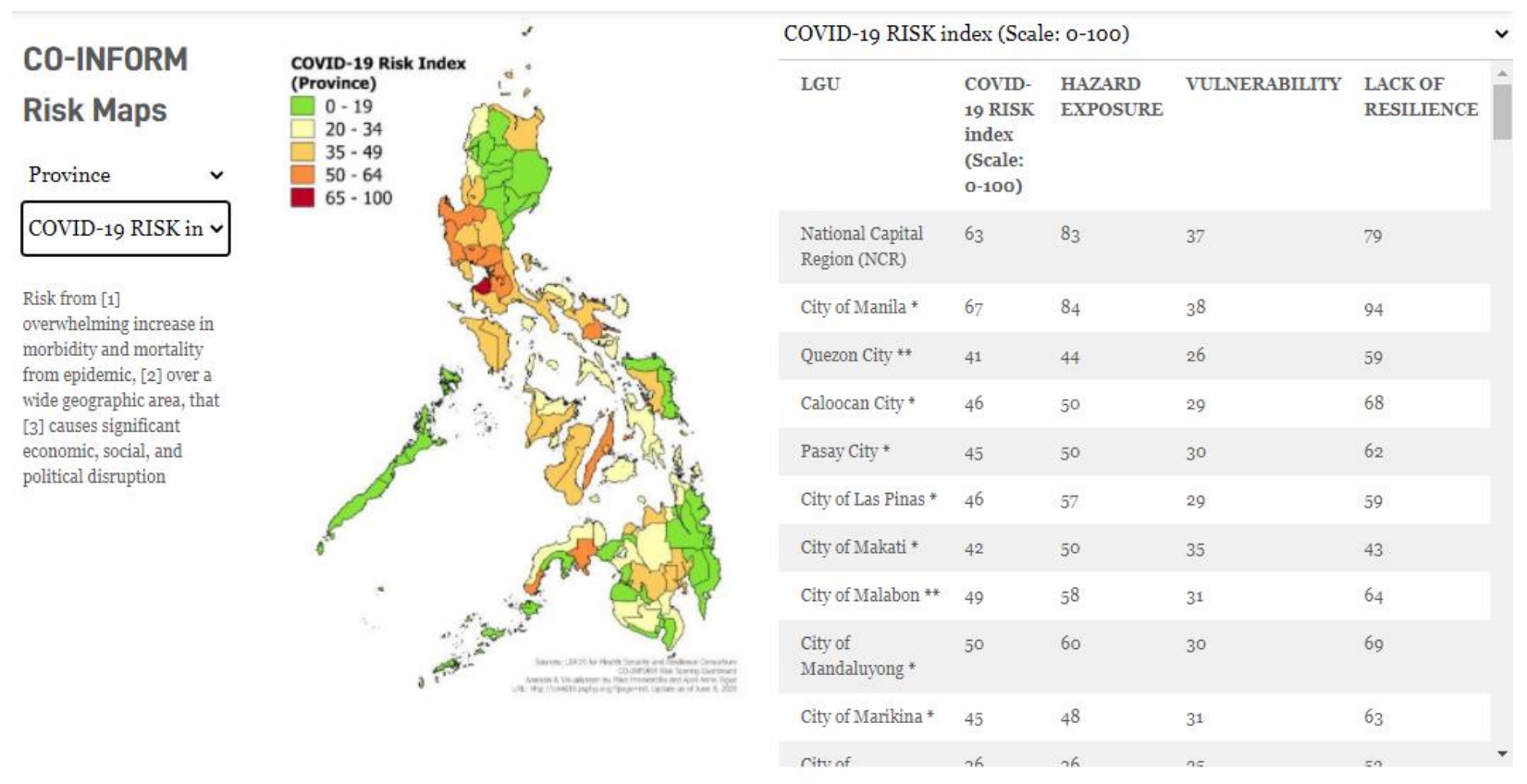

Figure 11: L4H CO-INFORM Risk Maps 


\section{Project AEDES}

Advanced Early Dengue Prediction and Exploration Service (AEDES) combines remote sensing with local climate data and Google search trends. The system identifies areas for prioritization based on search data, provides a nowcast of likely dengue cases combining search trends with temperature and precipitation readings from climate data, and from a combination of Fraction of Photosynthetically Active Radiation (FAPAR) and Normalized Difference Water Index (NDWI) readings from Landsat 8 and Sentinel 2, pinpoints areas with likely mosquito habitats (Ligot D. , Tayco, Toledo, \& Lopez, 2019).

AEDES was prototyped to address dengue-prone areas in the Philippines and was a winning entry in the 2019 NASA International Space Apps Challenge (CirroLytix, 2019-2021) and was recognized by the Group on Earth Observations for using Earth observations for sustainable development goals (GEO, 2020), and recently was approved as a Digital Public Good by the DPGA and UNICEF (DPGA, 2021).

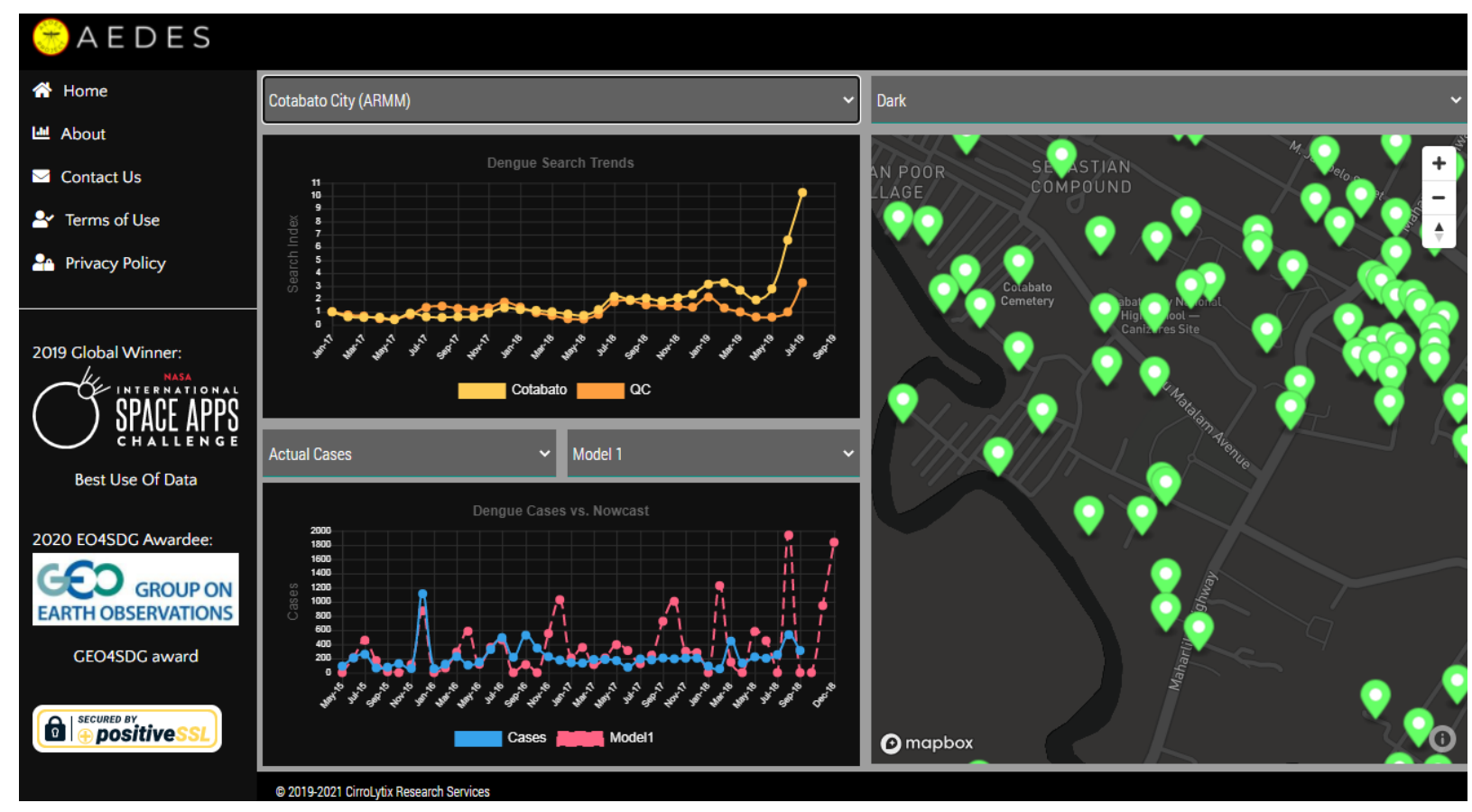

Figure 12: Project AEDES Dashboard ${ }^{14}$

14 (CirroLytix, 2019-2021) 


\section{GIDEON+}

Global Impact Detection from Emitted Light, Onset of COVID-19, and Nitrogen Dioxide (GIDEON+) combines $\mathrm{NO}_{2}$ readings from Sentinel $5 \mathrm{p}$ and night lights readings from VIIRS with COVID-19, mobility, and economic data to provide a pandemic country assessment. The system looks to highlight countries that are able to restore their economic output and minimize new COVID-19 infections, while keeping pollution levels under control. GIDEON+ was a winning entry in the 2020 NASA COVID-19 Space Apps Challenge (Barrameda, Zapata, Tan, \& Castelo, 2020).

Country

Information

Select a country to generate mobility, color separation and GDP datasets. Select map layers to overlay satellite indicators on the

Philippines

Night Lights

Retail

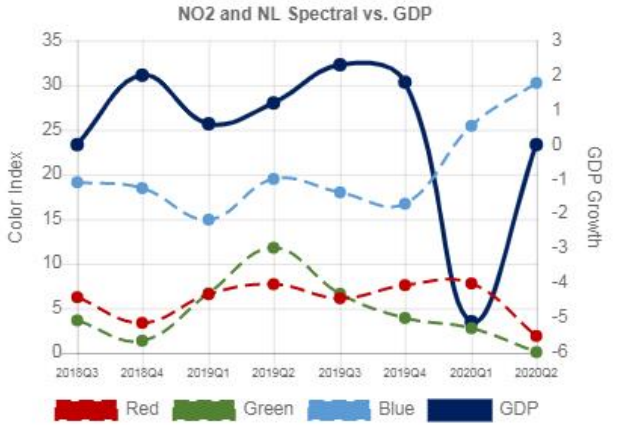

Figure 13: GIDEON+ Dashboard ${ }^{15}$

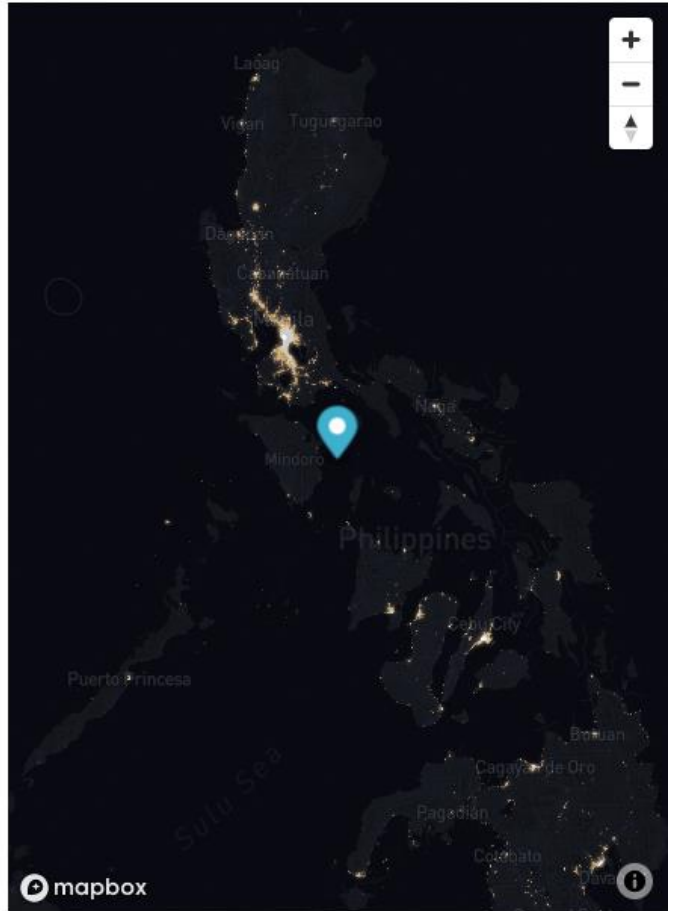

(1)

15 (Barrameda, Zapata, Tan, \& Castelo, 2020) 


\section{Global HEARTBEAT}

Global Hazard Exposure and Resilience Trends by Earth observations and Analysis Tools (Global HEARTBEAT) is built on the INFORM risk framework. The interactive tool combines demographic and socioeconomic statistics from the NASA Socioeconomic Data and Applications Center (SEDAC) (NASA, Socioeconomic Data and Applications Center (SEDAC), 1997-2021) with climate data from remote sensing and health surveillance data to provide a holistic assessment of populations for Philippines and Canada. Global HEARTBEAT was a Global Nominee in the 2020 NASA International Space Apps Challenge (Soong, Pascual, Vizmonte, Melendres, \& Brennan-Rieder, 2020).

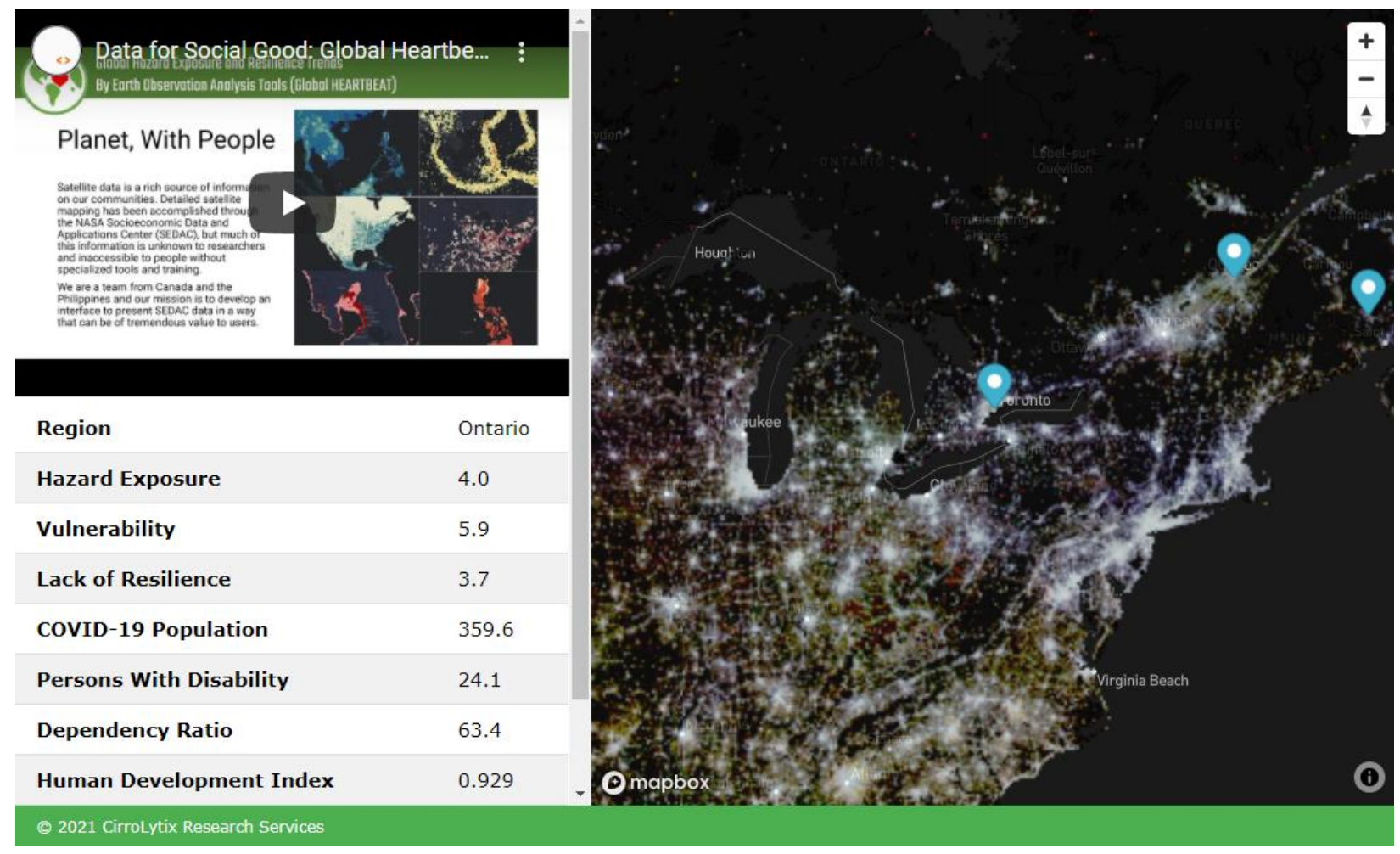

Figure 14: Global HEARBEAT Dashboard ${ }^{16}$

${ }^{16}$ (Soong, Pascual, Vizmonte, Melendres, \& Brennan-Rieder, 2020) 


\section{MAQI}

Movement over Air Quality Index (MAQI) is derived from Google mobility statistics and NO2 readings from Sentinel $5 \mathrm{p}$ TROPOMI. The objective for measuring MAQI is to measure locations that are recovering mobility from COVID-19 lockdowns but are managing to keep their pollution levels down. This provides a metric that captures both environmental and social behaviors, that can be used to contextualize public health surveillance and socioeconomic data. MAQI was a Global Finalist in the 2021 EO Dashboard Hackathon (Domagas, Caronongan III, Pascual, \& Ligot, 2021).
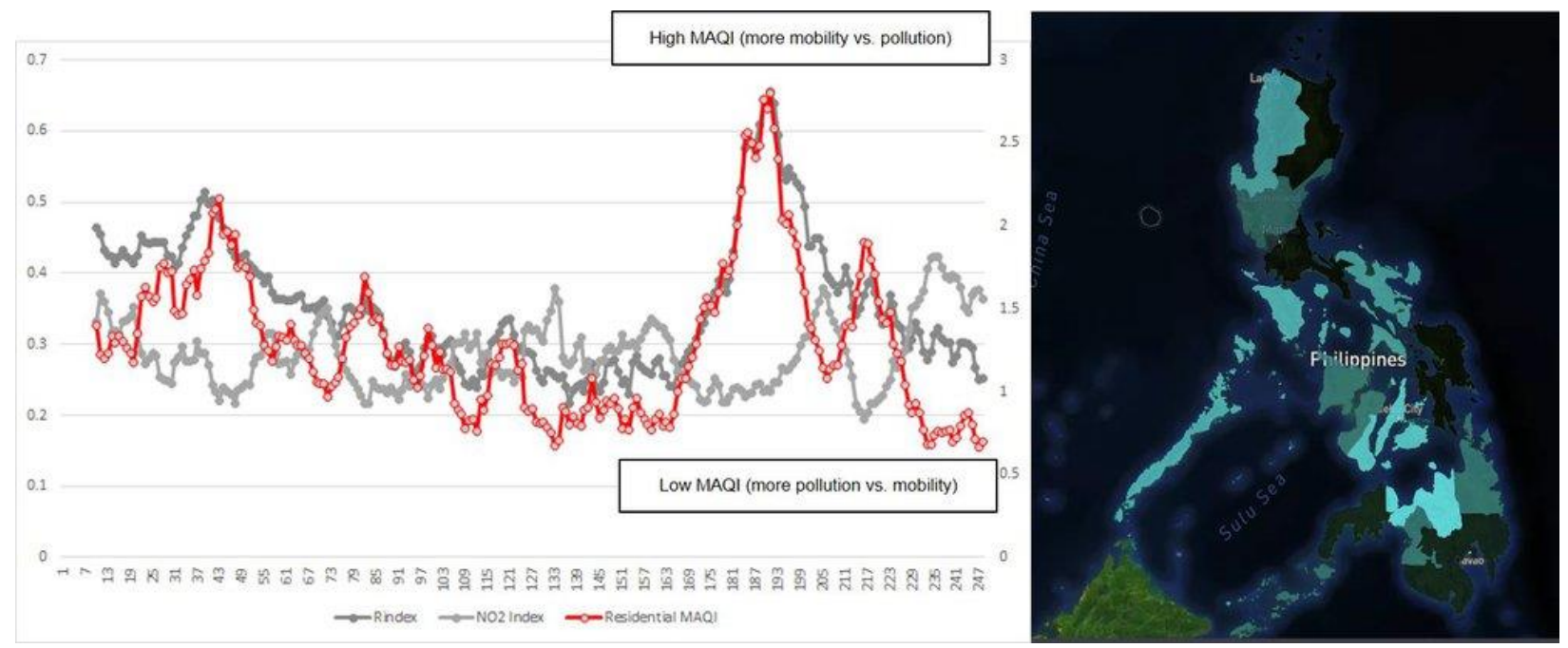

Figure 15: MAQI Graph and Choropleth Map 17

\section{Summary and Considerations for Further Work}

In this paper, we briefly discussed various data gathering methods in public health such as rapid assessments, surveys, and surveillance. Types of public health surveillance were also discussed such as passive, active, sentinel, and syndromic surveillance. We presented the common challenges encountered in surveillance such as location bias, denominator problems, as well as lack of granularity. We presented the potential for big data use in public health and started our focus on datasets from social listening such as Facebook and Twitter posts and Google Search Trends, and continued with data from remote sensing from Earth observation satellites, and finally a discussion on mobility indices gathered by Apple, Google, and Facebook. We discussed the challenges of using compartmental models in generating metrics during an ongoing pandemic due to the natural lags in reporting frequencies and presented the time varying reproductive number or $\left(R_{t}\right)$ as a reliable alternative to the basic reproductive number $\left(R_{0}\right)$. The paper presented the INFORM risk management model as a framework for integrating data from a wide variety of sources and discussed modalities for building decision support systems for surveillance such as diagnostic, design, planning and control. We then discussed selected examples of big data surveillance systems.

Although machine learning and AI applications were not discussed in this paper, they merit a separate discussion as they are integral to the maximization of big data and epidemic modeling (Fang, Tzeng, Chen, \& Chou, 2010).

17 (Domagas, Caronongan III, Pascual, \& Ligot, 2021) 
Big data holds great potential in providing basis for actionable policy interventions and public health response however, adoption remains nascent due to lack of innovation push within the public health sectors and the general distrust of non-traditional data sources. Most of the work presented here were products of innovation challenges and hackathons, which naturally invite the use of novel techniques. At the same time, there is also little governance in the use of the new data, particularly for social media, which contain personal information. As the practice for data use and modeling matures, consideration for privacy and ethical use has to evolve (Buckee, 2020).

The effective deployment of big data requires a wide set of skills, from data science to computer engineering, beyond the scope of most public health surveillance departments (Buckee, 2020). In most countries, surveillance systems remain based on manually collected data, which is prone to time lags and lack of granularity (Bansal, Chowell, Simonsen, Vespignani, \& Viboud, 2016). The COVID-19 pandemic has not only forced professionals and economies to embrace digital transformation, but also highlighted the need to invest in better technologies and broader strategies for health surveillance to shield against future pandemics (Buckee, 2020).

\section{Acknowledgements}

The author would like to thank Claire, Mark, Cricket, Emily, Rache, Mark Neil, Sam, Jhen, Mike, Art, Helen, Kristel, Oscar, Tessa, Peter, Mike P., Jan, April, Jomar, and Robert, the talented individuals who powered the projects described herein.

\section{Works Cited}

Apple. (2020-2021). Mobility Trends Reports. Retrieved from Apple.com: https://covid19.apple.com/mobility

Bansal, S., Chowell, G., Simonsen, L., Vespignani, A., \& Viboud, C. (2016). Big Data for Infectious Disease Surveillance and Modeling. The Journal of Infectious Diseases, S375-S379. doi:https://doi.org/10.1093/infdis/jiw40o

Barrameda, H., Zapata, K., Tan, T., \& Castelo, O. (2020). GIDEON. Retrieved from NASA COVID-19 Space Apps Challenge: https://covid19.spaceappschallenge.org/challenges/covidchallenges/integrated-assessment/teams/gideon/project

Buckee, C. (2020). Improving epidemic surveillance and response: big data is dead, long live big data. The Lancet, Digital Health. doi:https://doi.org/10.1016/S2589-7500(20)30059-5

Cayton, P., Sarmiento, J., Promentilla, M., Tigue, A., Leong, R., Ligot, D., . . Rabajante, J. (20202021). L4H COVID Dashboard. Retrieved from LEADS for Health Security and Resilience Consortium: https://covid19.psphp.org/

Cechini, M. (2021). GIBS API for Developers. Retrieved from NASA Earth Data: https://wiki.earthdata.nasa.gov/display/GIBS/GIBS+API+for+Developers

CirroLytix. (2019-2021). Advanced Early Detection and Exploration Service. Retrieved from Project AEDES: https://aedesproject.org/\#contact

Cooper, I., Mondal, A., \& Antonopoulos, C. (2020). A SIR model assumption for the spread of COVID-19 in different communities. Chaos, Solitons \& Fractals, 110057. doi:https://doi.org/10.1016/j.chaos.2020.110057 
Cori, A., Ferguson, N., Fraser, C., \& Cauchemez, S. (2013). A new framework and software to estimate time-varying reproduction numbers during epidemics. American Journal of Epidemiology, 1505-1512. doi:https://doi.org/10.1093/aje/kwt133

CrowdTangle Team. (2021). (Facebook, Menlo Park, California, United States.) Retrieved from CrowdTangle: https://help.crowdtangle.com/en/articles/3192685-citing-crowdtangle-data

Davidson, M., Haim, D., \& Radin , J. (2015). Using Networks to Combine "Big Data" and Traditional Surveillance to Improve Influenza Predictions. Scientific Reports. doi:https://doi.org/10.1038/srepo8154

De, R., Pandey, N., \& Pal, A. (2020). Impact of digital surge during Covid-19 pandemic: A viewpoint on research and practice. International Journal of Information Management. doi:https://doi.org/10.1016/j.ijinfomgt.2020.102171

Doherty, B., Marin-Ferrer, M., \& Vernaccini, L. (2018). INFORM Epidemic Risk Index. JRC Technical Reports. Retrieved from https://drmkc.jrc.ec.europa.eu/inform-index/INFORMRisk/INFORM-Epidemic-Risk-Index

Domagas, M., Caronongan III, A., Pascual, M., \& Ligot, D. (2021). World MAQI. Retrieved from EO Dashboard Hackathon: https://www.eodashboardhackathon.org/challenges/interactivedata-exploration/multi-mission-earth-observation-data-visualization/teams/worldmaqi/project

DPGA. (2021). UNICEF Philippines announces its first Digital Public Good Pathfinding Pilot. Retrieved from Digital Public Goods Alliance: https://digitalpublicgoods.net/blog/unicefphilippines-announces-its-first-digital-public-good-pathfinding-pilot/

Facebook. (2020-2021). Movement Range Maps. Retrieved from HDX: https://data.humdata.org/dataset/movement-range-maps

Fang, Z.-H., Tzeng, J.-S., Chen, C., \& Chou, T.-C. (2010). A Study of Machine Learning Models in Epidemic Surveillance: Using the Query Logs of Search Engines. PACIS 2010 Proceedings. Retrieved from https://aisel.aisnet.org/pacis2010/137/

GEO. (2020). Announcing the winners of the 2020 Earth Observation for the Sustainable Development Goals Awards. Retrieved from Group on Earth Observations: https://www.earthobservations.org/geo_blog_obs.php?id=472

Google. (2015). Google Flu Trends. Retrieved from Google.com: https://www.google.com/publicdata/explore?ds=z3bsqef7ki44ac_\#!ctype=l\&strail=false\&bc

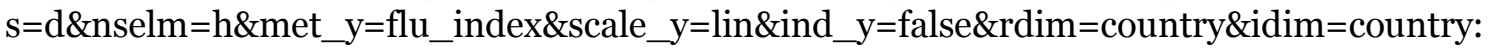
US\&ifdim=country\&hl=en_US\&dl=en_US\&ind=false

Google. (2020-2021). COVID-19 Community Mobility Reports. Retrieved from Google.com: https://www.google.com/covid19/mobility/

Google. (2021). Google Earth Engine. Retrieved from Google.com: https://earthengine.google.com/\#!/

Hamzah, F., Lau, C., Nazri, H., \& Ligot, D. (2020). CoronaTracker: World-wide COVID-19. Bulletin of the World Health Organization. doi:http://dx.doi.org/10.2471/BLT.20.255695 
Hilton, J., \& Keeling, M. (2020). Estimation of country-level basic reproductive ratios for novel Coronavirus (SARS-CoV-2/COVID-19) using synthetic contact matrices. PLoS Computational Biology. doi:https://doi.org/10.1371/journal.pcbi.1008031

Hopgood, A. (2000). Intelligent Systems for Engineers and Scientists. CRC Press.

Hussain, A., Tahir, A., Hussain, Z., Sheikh, Z., Gogate, M., Dashtipour, K., \& Sheikh, A. (2020). Artificial intelligence-enabled analysis of UK and US public attitudes on Facebook and Twitter towards COVID-19 vaccinations. medRxiv. doi:https://doi.org/10.1101/2020.12.08.20246231

Jovanovic, P. (1987). Remote sensing of environmental factors affecting health. Advances in Space Research(3), 11-18. doi:https://doi.org/10.1016/0273-1177(87)90118-9

Keeling, M., \& Rohani, P. (2008). Modeling Infectious Diseases in Humans and Animals. Princeton University Press.

Ligot, D., Tayco, F., Toledo, M., \& Lopez, J. (2019). AEDES Project. Retrieved from 2019 NASA International Space Apps Challenge: https://2019.spaceappschallenge.org/challenges/livingour-world/smash-your-sdgs/teams/aedes-project/project

Ligot, D., Tayco, F., Toledo, M., Nazareno, C., \& Brennan-Rieder, D. (2021). Infodemiology: Computational Methodologies for Quantifying and Visualizing Key Characteristics of the COVID-19 Infodemic. SSRN Coronavirus \& Infectious Disease Research eJournal. doi:https://dx.doi.org/10.2139/ssrn.3771695

Marin-Ferrer, M., Vernaccini, L., \& Poljansek, K. (2017). INFORM Index for Risk Management. JRC Science for Policy Report. Retrieved from https://drmkc.jrc.ec.europa.eu/informindex/INFORM-Risk/INFORM-Epidemic-Risk-Index

NASA. (1997-2021). Socioeconomic Data and Applications Center (SEDAC). Retrieved from Columbia.edu: https://sedac.ciesin.columbia.edu/

NASA. (2021). Remote Sensors. In Earth Data Open Access for Open Science. Retrieved from https://earthdata.nasa.gov/learn/remote-sensors

NASA. (2021). What is Remote Sensing? In Earth Data Open Access for Open Science. Retrieved from https://earthdata.nasa.gov/learn/backgrounders/remote-sensing

NASA. (2021). Worldview. Retrieved from NASA.gov: https://worldview.earthdata.nasa.gov/?v=118.31942508179439,63.57842410029712,126.58621640049735,68.07713930391031\&lg=true\&tr=worldview_intr $\mathrm{o} \& \mathrm{t}=2021-07-30-\mathrm{T} 14 \% 3 \mathrm{~A} 20 \% 3 \mathrm{~A} 18 \mathrm{Z}$

Poljansek, K., Vernaccini, L., \& Marin-Ferrer, M. (2020). INFORM Covid-19 Risk Index. JRC Technical Report. Retrieved from https://drmkc.jrc.ec.europa.eu/inform-index/INFORMCovid-19

Sinergise. (2021). Sentinel Hub. Retrieved from Euro Data Cube: https://www.sentinel-hub.com/

Soong, G., Pascual, M., Vizmonte, E., Melendres, R., \& Brennan-Rieder, D. (2020). Global HEARTBEAT. Retrieved from 2020 NASA International Space Apps Challenge: https://2020.spaceappschallenge.org/challenges/sustain/planet-people/teams/globalheartbeat/members 
Stone, K., \& Horney, J. (2018). Chapter 2 - Methods: Surveillance. In Disaster Epidemiology (pp. 1123). doi:https://doi.org/10.1016/B978-0-12-809318-4.00002-2

UNCTAD. (2021). How COVID-19 triggered the digital and e-commerce turning point. Retrieved from UNCTAD.org: https://unctad.org/news/how-covid-19-triggered-digital-and-ecommerce-turning-point

van den Driessche, P. (2017). Reproduction numbers of infectious disease models. Infectious Disease Modeling, 2(3), 288-303. doi:https://doi.org/10.1016/j.idm.2017.06.002

Woodruff, B., Bornemisza, O., Checchi, F., \& Sondorp, E. (2009). Comparison with other data collection methods. Retrieved from The use of epidemiological tools in conflict-affected populations: open-access educational resources for policy-makers:

http://conflict.lshtm.ac.uk/page_72.htm

Woodruff, B., Bornemisza, O., Checchi, F., \& Sondorp, E. (2009). Incomplete reporting. Retrieved from The use of epidemiological tools in conflict-affected populations: open-access educational resources for policy-makers:

http://conflict.lshtm.ac.uk/page_8o.htm\#Surveillance_Incomplete_reporting

Woodruff, B., Bornemisza, O., Checchi, F., \& Sondorp, E. (2009). Inherent problems. Retrieved from The use of epidemiological tools in conflict-affected populations: open-access educational resources for policy-makers:

http://conflict.lshtm.ac.uk/page_79.htm\#Surveillance_Inherent_problems).

Woodruff, B., Bornemisza, O., Checchi, F., \& Sondorp, E. (2009). Types of surveillance. Retrieved from The use of epidemiological tools in conflict-affected populations: open-access educational resources for policy-makers: http://conflict.lshtm.ac.uk/page_75.htm

Yang, S., Kou, S., Lu, F., Brownstein, J., Brooke, N., \& Santillana, M. (2017). Advances in using Internet searches to track dengue. PLoS Computational Biology. doi:https://doi.org/10.1371/journal.pcbi.1005607 